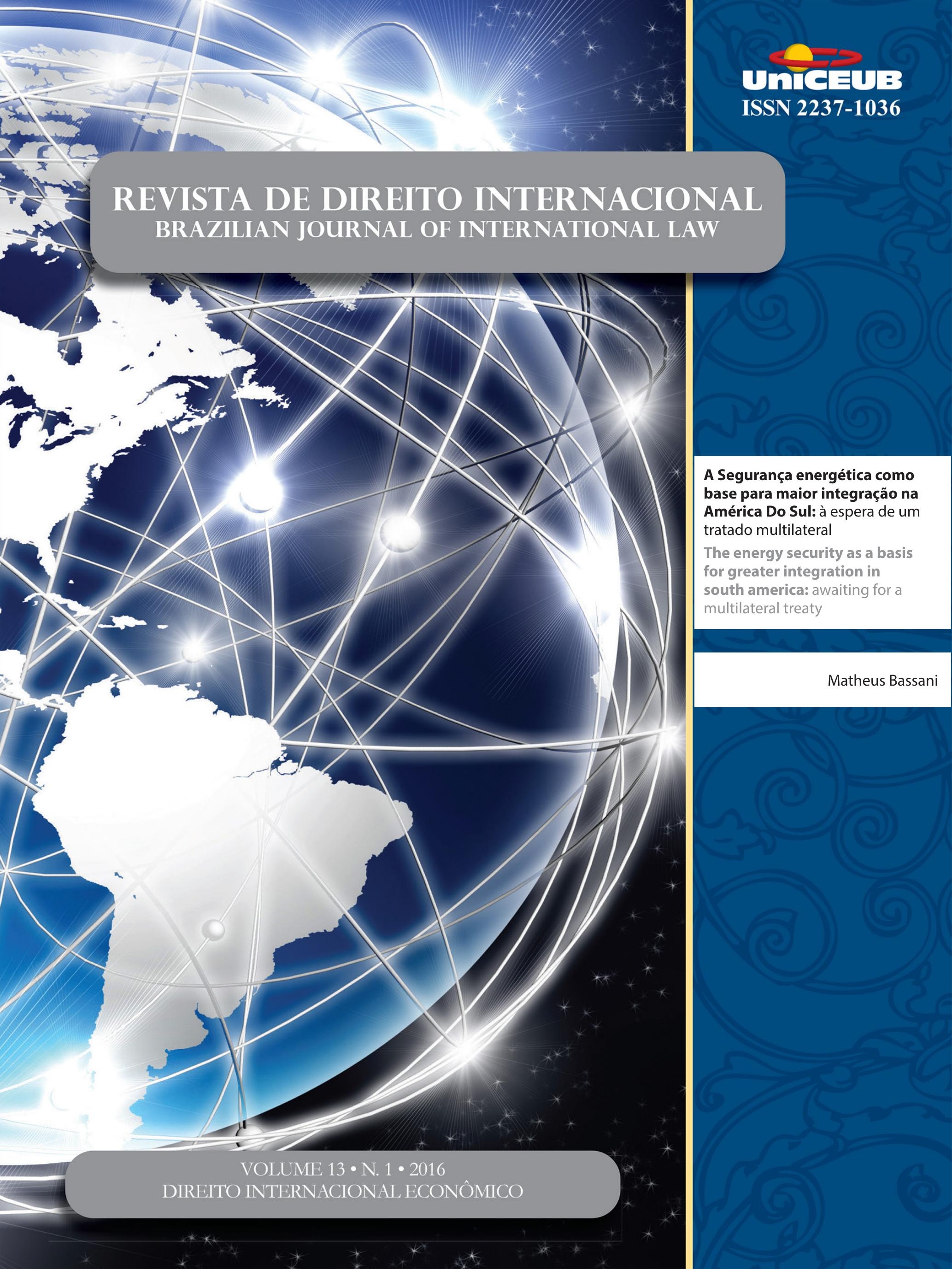




\section{Sumário}

Dossiê Temático: Direito Internacional Econômico.........................................................1

EDITORIAL:

Resultados da III Conferência Bienal da Red DEI ................................................. 3

Michelle Ratton Sanchez-Badin (em nome da Diretoria da Red DEI), Fabio Costa Morosini e Lucas da Silva Tasquetto (em nome dos organizadores da III Conferência da Red DEI)

Direito Internacional Econômico no Brasil: QUem Somos E o QUE faZemos? EvidênCIas EMPÍRICAS DE 1994 A 2014

Michelle Ratton Sanchez Badin, Fabio Costa Morosini e Inaê Siqueira de Oliveira

UM ESPAÇO PARA PENSAR EM ALTERNATIVAS? A ACADEMIA LATINO-AMERICANA DE DIREITO INTERNACIONAL ECONÔMICO FRENTE À ORDEM ECONÔMICA GLOBAL

Nicolás Marcelo Perrone

Grupo de alto Nível Brasil - Urugua (GAN): um Novo paradigma para a INTEgraÇão PRODUTIVA NO MERCOSUL

Alebe Linhares Mesquita e Vivian Daniele Rocha Gabriel

O COMÉRCIO de SERVIÇOS ENTRE Brasil E URUGUAI: LiberalizaÇÃo, DESAFIOS E PERSPECTIVAS DO SETOR DE TECNOLOGIA DA INFORMAÇÃO E COMUNICAÇÃO (TIC) E SOFTWARES

Vivian Daniele Rocha Gabriel e Alebe Linhares Mesquita

Core Labor Standards No Regime de PREFERÊNCIAS TARIFÁrias No MERCOSUL: A NeCESSIDADE DE HUMANIZAÇÃO DO COMÉRCIO INTERNACIONAL

Martinho Martins Botelho e Marco Antônio César Villatore

ACordo TRIMS: FleXibilizaÇão ou Não? Política de CONTEÚdo loCal, PROCESSO PROdUTIVO BÁSICO (PPB) E OS DESAFIOS PARA A INDÚSTRIA BRASILEIRA E A INTEGRAÇÃo LATINO-AMERICANA 100

Natália Figueiredo 
ESTUDIOS DE CASO DE RECHAZOS EN FRONTERA DE EXPORTACIONES ALIMENTARIAS LATINOAMERICANAS POR MOTIVOS RELACIONADOS CON MEDIDAS TÉCNICAS NO ARANCELARIAS.

Sofía Boza, Juan Rozas e Rodolfo Rivers

América do Sul em face dos tratados bilaterais de inVESTimento: RUMO aO RETORNo do EsTADO NA SOLUÇão DE CONTROvÉRSIAS? 133 Magdalena Bas

FutURo DE LOS SISTEMAS NACIONALES DE CIENCIA TECNOLOGÍA E INNOVACIÓN EN LA AGENDA ECONÓMICA DE AMÉRICA LATINA: DEFINIENDO CAMBIOS REGULATORIOS O PROTEGIENDO INVERSIONES 146

Rodrigo Corredor

EL PAPEL DE LAS INSTITUCIONES DE CONTROL FINANCIERO SOBRE LOS DERECHOS HUMANOS EN EL CONTEXTO LATINOAMERICANO 157 Jose Miguel Camacho Castro

CONVERGENCIA REgUlATORIA EN LA ALIANZA DEL PACÍFICO: UN CAPÍTULO INCONCLUSO 170 Rodrigo Polanco Lazo

O CONSTITUCIONALISMO E A COMUNITARIZAÇÃO NO DIREITO INTERNACIONAL: POSSIBILIDADES PARA O COMÉRCIO INTERNACIONAL?

Camilla Capucio

ESCASSEZ HÍDRICA E DIREITO INTERNACIONAL ECONÔMICO: O BRASIL COMO PROTAGONISTA NA TRANSFERÊNCIA DE ÁGUA PARA REGIÕES ÁRIDAS

Douglas de Castro

A Segurança energética como base para maior integração na América Do Sul: à espera DE UM TRATADO MULTILATERAL

Matheus Bassani

Outros Artigos. 246

As PRÁtICAS RESTRITIVAS DA CONCORRÊNCIA NO MERCADO DE CONTRATAÇÃo PÚBLICA EUROPEU .. 248 Alice Rocha da Silva e Ruth M. P. Santos 
Do TRANSNACIONAL PARA O NACIONAL: IOSCO, O MERCADO DE VALORES MOBILIÁRIOS BRASILEIRO E ACCOUNTABILITY

Salem Nasser, Nora Rachman e Viviane Muller Prado

MigRaÇÃo de TRABALHADORES INTELECTUAIS BRASILEIROS PARA O MERCADO INTERNACIONAL: IDENTIFICAÇÃO DE ATOS DE ALICIAMENTO DE EMPREGADOS E MECANISMOS LEGAIS PARA IMPEDIR A APROPRIAÇÃo TECNOLÓGICA E CONCORRÊNCIA DESLEAL ..........................................285 José Carlos Vaz e Dias e João Marcelo Sant'Anna da Costa

THE EASIER WAY TO HAVE "BETTER LAW"? THE MOST-SIGNIFICANT-RELATIONSHIP DOCTRINE AS THE FALLBACK CONFLICT-OF-LAW RULE IN THE PEOPLE'S REPUBLIC OF CHINA

Chi Chung

REFLEXOS JURÍDiCOS DA GOVERNANÇA GLOBAL SUBNACIONAL: A PARADIPLOMACIA E O DIREITO INTERNACIONAL: DESAFIO OU ACOMODAÇÃO 320

Valéria Cristina Farias e Fernando Rei

Matrizes Políticas da JUSTiÇA PENAL INTERNACIONAL. 341 Francisco Rezek

RESPONSABILIDAD INTERNACIONAL DEL ESTADO FRENTE A LUCHA CONTRA LA DISCRIMINACIÓN RACIAL Y ÉTNICA EN ESPAÑA. 348

Edilney Tomé da Mata e Eduardo Biacchi Gomes Correio

The Peace Process in Sierra Leone: an analysis on marriages between culture and CRIME

Gustavo Bussmann Ferreira

Funcionalização e expansão do Direito Penal: o Direito Penal negocial ...............376 Antonio Henrique Graciano Suxberger e Dermeval Farias Gomes Filho

Proteção Internacional do Consumidor e Cooperação Interjurisdicional .396 Héctor Valverde Santana e Sophia Martini Vial

The land rights of indigenous and traditional peoples in Brazil and Australia.... 418 Márcia Dieguez Leuzinger e Kylie Lyngard 
The reception of European ideas in Latin America: the issue of the German sources in Tobias Barreto, A Prominent nineteenth CENTURy BraZilian legal scholar........439 Arnaldo Sampaio de Moraes Godoy

Normas Editoriais ..................................................................................... 461 


\title{
A Segurança energética como base para maior integração na América Do Sul: à espera de um tratado multilateral*
}

\author{
The energy security as a basis for greater \\ integration in south america: awaiting for a \\ multilateral treaty
}

Matheus Bassani**

\section{Resumo}

A União de Nações Sul-Americanas (UNASUL) é uma organização que possui como núcleo a busca pela integração entre os países da América Latina. Pode-se afirmar que ela tende a ser considerada um último suspiro na tentativa de organizar um bloco multicultural e dividido por tão-somente duas línguas. O objetivo deste trabalho é verificar se a segurança energética pode ser considerada como um catalisador para orientar a integração entre países localizados no continente. Utiliza-se do método dedutivo decorrente de pesquisa em obras nacionais e estrangeiras, base de dados e artigos eletrônicos. A segurança energética é base para a formatação de um acordo multilateral, assegurando estabilidade e previsão de abastecimento de recursos energéticos entre fornecedores e consumidores. O tema da energia é extremamente relevante como meio de integração considerando-se o requisito fundamental que é o estabelecimento de estruturas físicas compartilhadas, como linhas de transmissão de energia elétrica e dutos. Houve estudos sobre a possibilidade de o gás natural ser o centro de uma integração, que poderia estender o desenvolvimento a demais setores carentes da região. Benefícios mútuos são consequência de maior integração no setor de energia. Os membros da UNASUL desejam um plano conjunto para tornar mais eficiente a geração e consumo de energia, calcado no projeto de Tratado Energético Sul-Americano (TES). No entanto, inexiste previsão sobre a assinatura e efetividade do acordo, em fase de análise pelos chefes de Estado dos membros, tornando medidas bilaterais ou regionais uma saída para a ausência de vontade política. A abordagem do trabalho pretende salientar a importância de um marco regulatório para otimizar os fluxos energéticos.

Palavras-chave: Segurança energética. Integração energética. Tratado Energético Sul-Americano. Multilateralismo. UNASUL.

\section{Aprovado em 01/05/2016}

** Doutorando e mestre em Direito pela Universidade Federal do Rio Grande do Sul - UFRGS. Graduado em Ciências Jurídicas e Sociais, pela Pontifícia Universidade Católica do Rio Grande do Sul - PUCRS. Pesquisador visitante do Center for Energy, Petroleum and Mineral Law and Policy - CEPMLP, na Universidade de Dundee, Reino Unido. E-mail: matheusbassani@hotmail.com

\section{Abstract}

The organization called Union of South American Nations (UNASUL) brings the idea of integration between Latin America's countries. It tends to be considered a last breath in an attempt to organize a multicultural blo- 
ck and divided by merely two languages. The objective of this work is to verify energy security as a catalyst to guide the integration of countries located in South America. Therefore, deductive method is used based on research in national and foreign works and electronic database. Energy security is the basis for formatting a multilateral agreement, ensuring stability and forecast supply of energy resources between suppliers and consumers. The theme of energy is extremely relevant and can become a catalyst to guide the integration, mainly due to the fundamental requirement of establishing shared physical structures such as power lines and pipelines. There have been studies on the possibility of natural gas be the center of an integration, which could extend the development to other sectors of the region. Mutual benefits are the result of greater integration in the energy sector. The members of UNASUR want a joint plan to make more efficient energy generation and consumption, based on the South American Energy Treaty project (TES). However, there is no prediction on the execution and effectiveness of the agreement, which is under review by the heads of state members. Bilateral or regional agreements are an exit to the lack of political will. The work aims to stress the importance of a framework to optimize the energy flow.

Keywords: Energy security. Energy integration. South American Energy Treaty. Multilateralism. UNASUL

\section{INTRODUÇÃo}

O presente artigo pretende identificar se os países localizados na América do Sul necessitam se integrar de forma mais efetiva em busca de maior segurança energética. Trabalha-se com a hipótese de que os benefícios decorrentes da integração, como o desenvolvimento socioeconômico, poderão ser conquistados mediante um acordo multilateral dentro da UNASUL, como o Tratado de Energia Sul-Americano (TES).

Para se avaliar a confirmação da hipótese desta pesquisa, utilizar-se-á do método dedutivo, mediante análise doutrinária, nacional e estrangeira, além de base de dados científicos.

Inicialmente, será brevemente exposto o cenário atual energético na América do Sul, para posteriormente analisar o fundamento da segurança energética para maior integração. A necessidade de integração é justifi- cada pela possibilidade de benefícios mútuos entre os países, seja nos aspectos econômicos, políticos e físicos, mediante o compartilhamento de estruturas capazes de dinamizar o fluxo de recursos energéticos.

O Tratado Constitutivo da UNASUL provê bases regulatórias para se tornar uma instituição fundamental para a aprovação de um Tratado Energético Sul-Americano, que já possui uma estrutura sugerida pelo Conselho Energético Sul-Americano. No entanto, parece que a vontade dos membros esvaiu-se nos últimos anos.

Isso torna o projeto de integração mais utópico e fomenta ações bilaterais ou regionais, que não são as ideais, mas permitem alguma evolução no intuito de fornecer bases para maior segurança energética e para um desenvolvimento pontual. Nesse sentido, a integração energética do continente perpassa por um período de maturação, cujos indícios de agravamento da situação econômica de países consumidores e produtores, como Argentina, Brasil e Venezuela, devem postergar a aprovação de um tratado multilateral.

\section{Breve anÁlise do Cenário atual}

Acordos regionais, como a Comunidade Andina das Nações (CAN), o Mercosul, e recentemente, a União de Nações Sul-Americanas (UNASUL) compõem a ideia de uma integração entre os países da América Latina. Pode-se afirmar que esse último acordo tende a ser considerado um último suspiro na tentativa de organizar um bloco multicultural e dividido por tão somente duas línguas.

Em relação a esse ponto, é possível identificar que as organizações não estão sobrepostas umas às outras em relação aos seus objetivos, por possuírem funções complementares para superar os obstáculos ao processo de integração Sul-Americano. A UNASUL tende a incentivar a criação de uma área de livre-comércio (ALC) na América do Sul, mediante uma aproximação entre Mercosul e Comunidade Andina, mas vai mais além do que uma ALC, colaborando para a construção de entendimentos entre os países e para a formação de uma identidade política sul-americana. ${ }^{1}$

1 OLIVEIRA, Ana Carolina Vieira de; SALGADO, Rodrigo Souza. Modelos de integração na América do Sul: do Mercosul à Unasul. In: ENCONTRO NACIONAL ABRI 2001. 3., 2011, São Paulo. Proceedings... Associação Brasileira de Relações Internacionais Insti- 
Mais precisamente, a UNASUL não pretende somente integrar os seus membros no âmbito estritamente econômico, mas prevê, também, uma integração cultural, social, política, entre outras, conforme artigo $2^{\circ}$, do Tratado Constitutivo da União das Nações Sul-Americanas (TCUNASUL), in verbis:

La Unión de Naciones Suramericanas tiene como
objetivo construir, de manera participativa y
consensuada, un espacio de integración y unión en lo
cultural, social, económico y político entre sus pueblos,
otorgando prioridad al diálogo político, las políticas
sociales, la educación, la energía, la infraestructura,
el financiamiento y el medio ambiente, entre otros,
con miras a eliminar la desigualdad socioeconómica,
lograr la inclusión social y la participación ciudadana,
fortalecer la democracia y reducir las asimetrías
en el marco del fortalecimiento de la soberanía e
independencia de los estados.

O tema da energia é extremamente relevante, e pode se tornar um catalisador para orientar a integração, principalmente em razão do requisito fundamental do estabelecimento de estruturas físicas compartilhadas, como linhas de transmissão de energia elétrica e dutos. Houve estudos sobre a possibilidade de o gás natural ser o centro de uma integração ${ }^{2}$, que poderia estender o desenvolvimento a outros setores carentes da região.

No entanto, com exceção dos gasodutos Brasil-Bolívia (Gasbol), Argentina-Bolívia e Argentina-Chile, parece que decisões políticas acabam obstando os planos estratégicos acordados, como a construção do ambicioso Grande Gasoduto do Sul, vindo da Venezuela pelo Brasil interligando os gasodutos dos países do Mercosul, principalmente com o Gasbol.

Diferentemente dos reduzidos acordos bilaterais existentes hoje, os membros da UNASUL desejam um plano conjunto para tornar mais eficiente a geração e consumo de energia, calcado no projeto de Tratado Energético Sul-Americano (TES) ${ }^{34}$. No entanto, ine-

tuto de Relações Internacionais - USP. Disponível em: <http:// www.proceedings.scielo.br/scielo.php?script $=$ sci_arttext\&pid $=$ MS C0000000122011000100011\&lng $=$ en\&nrm $=$ abn $>$. Acesso em: 07 ago. 2015.

2 ZANELLA, Cristine Koehler. Energia e integração: oportunidade e potencialidades da integração gasífera na América do Sul. Ijuí: Unijuí, 2009.

3 ORGANIZACION LATINO AMERICANA DE ENERGIA; UNIÃO DE NAÇÕES SUL-AMERICANAS. Un Espacio que Consolida la Integración Energética. Disponível em: < http://www.olade. $\mathrm{org} /$ sites/default/files/publicaciones/UNASUR $\% 20-\% 20$ Un $\% 20$ espacio\%20que\%20-completo.pdf>. Acesso em: 15 jan. 2015.

4 UNIÃO DE NAÇÕES SUL-AMERICANAS. Alinhamentos de estratégia energética sul-americanas. Disponível em: < http://www.un- xiste previsão sobre a assinatura e efetividade do acordo, hoje em fase de análise pelos chefes de Estado dos membros. ${ }^{5}$

O cenário econômico das tradicionais e principais economias do continente, como Argentina, Brasil e Venezuela, não está favorável para a realização de investimentos externos. Talvez, conjuntamente, ou com apoio de outros parceiros, públicos e/ou privados, possa emergir a viabilidade dos projetos se tornarem uma realidade.

Um obstáculo à integração é a assimetria socioeconômica entre os países, que pode causar distorções na hipótese de uma integração de mercado energético, em que cada membro possui regras próprias relativas à extração de recursos naturais, comércio, investimentos ${ }^{6}$, considerando-se a relevância dos bens a serem tratados, como petróleo, gás e energia elétrica. Facilitar o trânsito desses bens significa possibilitar o fornecimento de forma menos restritiva para outros mercados, podendo o preço local se ajustar conforme o preço praticado no contexto integrado, aumentando ou reduzindo.

O TES, futuramente, poderá ser o marco jurídico inicial para atingir esse tipo de integração, focado para uma otimização da infraestrutura, com maior segurança e autonomia energética.

\section{Fundamento de MAIOR INTEGRAÇÃo: A SEGURANÇA ENERGÉTICA}

A segurança energética é uma das principais preocupações de qualquer país que deseja ser considerado

asursg.org/images/descargas/ESTATUTOS\%20CONSEJOS $\% 20$ MINISTERIALES $\% 20$ SECTORIALES/LINEAMIENTOS $\% 20$ DE\%20ESTRATEGIA \%20ENERGETICA\%20SURAMERICANA.pdf>. Acesso em: 15 jan. 2015.

5 UNIÃO DE NAÇÕES SUL-AMERICANAS. Plano TES. Disponível em: <http://www.unasursg.org/uploads/e1/77/ e17787075555d52b60a86193c81d482b/PLAN-TRATADO-ENERGETICO-SURAMERICANO.pdf> e em <http://www.unasursg.org/uploads/4c/e6/4ce6db8f6ed4f4e72d157f868f640465/ Declaracio $\%$ CC $\% 81$ n-de-las-Autoridades-Nacionales-en-MateriaEnerge \%CC\%81 tica-Caracas-Venezuela-13-mayo-2011..pdf $>$. Acesso em: 15 jan. 2015.

6 ORGANIZACION LATINO AMERICANA DE ENERGIA. Potencialidades de recursos energeticos y minerales en america del sur: coincidencias juridicas hacia una estrategia regional. Disponível em: <http:// www.olade.org/sites/default/files/publicaciones/Potencial-Recursos-Energeticos-Minerales-AS.pdf>. Acesso em: 07 mar. 2016 
como potência no cenário mundial, além de proporcionar qualidade de vida à sua população. Quando se trata do tema, inevitavelmente se avalia o impacto econômico. A importação e exportação de energia pode causar substancial mudança na balança de pagamentos de um Estado. A receita estatal pode ser influenciada por subsídios, tributos ou receitas decorrentes de empresas estatais energéticas. Ainda, o custo da energia está diretamente ligado às taxas de inflação e em como o país compete no âmbito internacional com seus produtos. ${ }^{7}$

Políticas energéticas devem ser elaboradas com o fim de evitar a instabilidade no fornecimento de energia ao mercado interno do país. Seria possível pensar que, na hipótese de um país ser autossuficiente, nenhuma ação regulatória ou política seria necessário; no entanto, sua autossuficiência somente pode ter emergido com base em um sério planejamento de longo prazo. ${ }^{8}$

O que se pretende verificar é por quais meios a segurança energética pode ser alcançada. E isso dependerá de que lado o Estado se encontra, se na posição de produtor ou consumidor. A posição de produtor pode ser confortável na medida em que ele, teoricamente, controlaria quando, quanto e como venderia os recursos energéticos. Mas, certamente, não adiantaria possuir recursos se inexistissem os países consumidores. Cada país compreende seu potencial em intervir ou influenciar os demais, dependendo do poder relativo que possui, o que impactará, decisivamente, na forma como atuará no cenário internacional. ${ }^{9}$

Importante ressaltar que, ao se intensificar o comércio de energia, enraíza-se um conceito de interdependência entre os produtores e consumidores. Nesse contexto, medidas são necessárias para evitar a insegurança. Países que dependem da importação de recursos energéticos devem (i) adotar políticas destinadas a assegurar o acesso ao suprimento externo adicional que é essencial às necessidades domésticas e (ii) reduzir a necessi-

7 CORRELJÉ, Aad; VAN DER LINDE, Coby. Energy supply security and geopolitics: a European perspective, Energy Policy, v. 34, n. 5 , p. $532-543,2006$. p. 532.

8 BASSANI, Matheus Linck. Governança global de energia nas organizações intergovernamentais: necessária transição para uma energia sustentável. 2014. 201 f. Dissertação (Mestrado)-Programa de PósGraduação em Direito, Faculdade de Direito, Universidade Federal do Rio Grande do Sul, Porto Alegre, 2014. p. 41.

9 BASSANI, Matheus Linck. Governança global de energia nas organiz̧ações intergovernamentais: necessária transição para uma energia sustentável. 2014. 201 f. Dissertação (Mestrado)-Programa de PósGraduação em Direito, Faculdade de Direito, Universidade Federal do Rio Grande do Sul, Porto Alegre, 2014. p. 41. dade de acesso a suprimentos externos, para reduzir a dependência, do ponto de vista estratégico, e custos, do ponto de vista econômico. ${ }^{10}$

Para assegurar o acesso a suprimento externo, o país pode atuar em diversas frentes, não necessariamente ao mesmo tempo, como procurar relações bilaterais com os produtores, criar um sistema de fornecedores preferenciais, participar de acordos de comércio, oferecer assistência tecnológica, participar de organizações internacionais e contribuir com esforços internacionais mais amplos, como a AIE. ${ }^{11}$

A redução de necessidade de acesso a suprimentos externos pode ser efetivada mediante implementação de políticas de conservação, incentivos para desenvolvimento de energia alternativa, fomentar pesquisa e desenvolvimento, mais destinadas ao âmbito doméstico. Mas, basicamente, três interesses são fundamentais para o país dependente de recursos externos: (i) o suprimento de energia importada deve ser suficiente; se estiver abaixo do consumo, pode oferecer risco ao país; (ii) o suprimento de energia importada deve ser contínuo, sob pena de causar interrupções ou cortes causarem prejuízos sociais, políticos e econômicos; e (iii) a energia importada deve possuir preços razoáveis, refletindo, também, uma capacidade de pagar do importador. ${ }^{12}$

As vulnerabilidades existem e são fatores que acabam fornecendo uma vantagem comparativa aos países produtores em relação aos carentes de recursos. Para efetivamente evitar riscos à segurança energética, o fundamental e o ideal é possuir o controle ou o domínio das etapas, desde a extração até o consumo. Na teoria, seria o mesmo que poder controlar a operação vertical e horizontal da cadeia. No caso do petróleo e gás, o ideal seria controlar tanto o upstream (extração e produção) como o downstream (refino, venda e distribuição), o que envolve um substantivo esforço.

Um exemplo claro ocorreu com os membros da $\mathrm{OPEP}^{13}$, que concentram as maiores reservas e produ-

10 CONANT, Melvin A.; GOLD, Fern Racine. A geopolitica energética. Rio de Janeiro: Biblioteca do Exército, 1981. p. 19.

11 BASSANI, Matheus Linck. Governança global de energia nas organiz̧ações intergovernamentais: necessária transição para uma energia sustentável. 2014. 201 f. Dissertação (Mestrado)-Programa de PósGraduação em Direito, Faculdade de Direito, Universidade Federal do Rio Grande do Sul, Porto Alegre, 2014. p. 42.

12 CONANT, Melvin A.; GOLD, Fern Racine. A geopolitica energética. Rio de Janeiro: Biblioteca do Exército, 1981. p. 20.

13 Irã, Iraque, Kuwait, Arábia Saudita e Venezuela fundaram a 
zem maior quantidade de petróleo. Dados referentes até a década de 1980, o transporte estava sob controle de países não membros da OPEP e a maioria dos petroleiros pertenciam ou estavam alugados a uma companhia internacional de petróleo e os oleodutos se localizavam na Europa, Estados Unidos da América (EUA), Canadá e ex-União Soviética. ${ }^{14}$ Hoje, o transporte não está mais tão concentrado e os pipelines estão mais disseminados.

Em relação às refinarias, somente recentemente os países produtores iniciaram a processar o petróleo cru e exportando os seus derivados, como ocorre na Arábia Saudita. Anteriormente, as refinarias se concentravam nos países industrializados. O que se pode verificar é que, até a década de 1980, países da OPEP somente produziam o petróleo cru e exportavam para os países industrializados, que realizavam o transporte, o refino e detinham o mercado.

Hoje é possível identificar uma alteração desse quadro, não em relação à produção, que deverá se manter no Oriente Médio (grande parte) por muito tempo, mas em relação ao transporte e refino, ambos menos concentrados, e, também, ao mercado, que se desloca para o eixo asiático, diga-se Índia e China.

A alteração da matriz energética do petróleo para o gás, por exemplo, reduziria, substancialmente, a dependência, por exemplo, pelo aumento da produção de gás de xisto nos EUA. É possível afirmar que, ao investir em novas fontes alternativas, deixa-se de consumir um recurso energético, como o petróleo, reduzindo a vulnerabilidade. E, diante da forte dependência de recursos energéticos pelos países industrializados localizados no ocidente, em regra, os EUA e União Europeia, políticas externas são frequentemente acionadas no intuito de prover energia para o consumo. ${ }^{15}$

Importante ressaltar a distinção entre segurança energética de autonomia energética. A finalidade da segurança energética é reduzir os riscos de desabaste-

Organização dos Países Exportadores de Petróleo (OPEP). Entre 1960 e 1975, a organização expandiu para 13 membros, acrescido de Qatar, Indonésia, Líbia, Emirados Árabes Unidos, Argélia, Nigéria, Equador e Gabão. Hoje, a OPEP é composta por 12 Membros, sendo um suspenso - Equador em 1992 - e Gabão se retirou em 1995.

14 CONANT, Melvin A.; GOLD, Fern Racine. A geopolitica energética. Rio de Janeiro: Biblioteca do Exército, 1981. p. 25.

15 BASSANI, Matheus Linck. Governança global de energia nas organizações intergovernamentais: necessária transição para uma energia sustentável. 2014. 201 f. Dissertação (Mestrado)-Programa de PósGraduação em Direito, Faculdade de Direito, Universidade Federal do Rio Grande do Sul, Porto Alegre, 2014. p. 45. cimento, pois ser um país autônomo envolve uma dinâmica sui generis com altos custos e perspicaz planejamento de curto e longo prazo. Mitigar a dependência é um objetivo, mas muitas vezes difícil de ser alcançado quando se trata de grande escala de consumo. ${ }^{16}$

Essa lógica pode ser utilizada, também, na integração energética da América do Sul. Brasil e Argentina são os maiores consumidores, e enfrentam, sazonalmente, picos de consumo e desabastecimento. Do outro lado, Venezuela e Bolívia são os grandes fornecedores de petróleo e gás.

É possível identificar que os elementos suficiência, continuidade e preço razoável estão presentes no mercado latino. A Bolívia fornece gás ao Brasil desde o ano de 1999 (até São Paulo) e ano 2000 (até Porto Alegre), consumindo cerca de $75 \%$ de todo o gás exportado, o que comprova a possibilidade de estabelecer um contrato de longo prazo, apesar dos conflitos ocorridos no período, como a nacionalização do gás pela Bolívia, em 2006.

A Venezuela exporta a maioria do seu petróleo aos EUA, mas necessita de alternativas para evitar a dependência de um só mercado, o qual é, declaradamente, contra o seu governo. Nesse momento, o país sofre com a queda do preço do barril do petróleo, declinando de US\$ 110,00 para abaixo de US\$ 30,00 ao final do ano de 2015 (em 09/03/2016, o barril custa US\$ 37,00 ), fator que reduziu, drasticamente, suas receitas e agravando sua crise econômica. Diversificar mercados, e considerando a vantagem de situar-se no mesmo continente, pode ser uma saída, desde que incentivada, portanto, maior integração regional.

Em se tratando de diversificar fontes para maior segurança energética, a geração de energia elétrica por meio renovável é uma grande tendência, desde que as linhas de transmissão possam chegar aos consumidores e desde que haja uma regulação mais precisa sobre o setor, pois cada país possui suas regras peculiares.

\section{NeCESSÁRIA INTEGRAÇÃo ENERGÉTICA}

A integração se justifica pela necessidade de com-

16 ZANELLA, Cristine Koehler. Energia e integração: oportunidade e potencialidades da integração gasífera na América do Sul. Ijuí: Unijuí, 2009. p. 97. 
plementação dos mercados de energia entre os países da América do Sul, os quais podem ser identificados como importadores e exportadores de recursos energéticos, garantindo, portanto, maior segurança energética e maior autonomia em se tratando de escala continental ou regional.

Nesse estudo, considera-se integração regional em nível interestatal e não em nível infranacional, como pode ser também compreendido ${ }^{17}$. A CEPAL realizou um estudo analisando o conceito de integração ${ }^{18}$ :

In general, regional integration processes can be viewed from at least three angles:

1. Economic and trade integration, which includes different degrees or stages of integration (preferential trade agreements; free trade area; customs union; common market and economic and monetary union);

2. Political integration, which implies greater depth, coordination and harmonization of actions among members in the governmental and institutional sphere; and

3. Physical integration, featuring infrastructure and its services as the protagonists.

Interessante análise de João Moreira e Roberto Pinto, analisando-se a integração energética, possui como pressuposto, inicialmente, a integração de mercados de energia. Nesse sentido:

entenda-se por integração de mercados, o processo de intercâmbios de energia entre diferentes países considerando-se a possibilidade de companhias de todos os países participarem na geração e transmissão de energia em todos os países, e de condições conjuntas de otimização de recursos, harmonização de aspectos regulatórios, redução de custos e impactos ambientais, entre outros. ${ }^{19}$

No caso em concreto, verifica-se que a integração no setor de energia perpassa pelos três tipos de processos de integração referidos pela CEPAL, em razão que depende de um mercado para ser viabilizada, depende de coordenação e cooperação entre os atores envolvidos, e,

17 ZANELLA, Cristine Koehler. Energia e integracãa: oportunidade e potencialidades da integração gasiffera na América do Sul. Ijuí: Editora Unijuí, 2009. p. 83.

18 COMISSÃO ECONÔMICA PARA A AMÉRICA LATINA

E O CARIBE. Physical Infrastructure and Regional Integration. FAL Bulletin, v. 280, n. 12, 2009.

19 MOREIRA, João Manoel Losada; PINTO, Roberto Tadeu Soares. Integração energética ou integração de mercados: qual é a melhor solução para a comercialização de energia elétrica? In: CONGRESO DE LA ASOCIACIÓN LATIONAMERICANA DE ECONOMÍA DE LA ENERGÍA, 4., 2013, Montevideo. Anais. 2013. p. 1-2. principalmente, de um compartilhamento de infraestrutura, por se tratar de redes interconectadas.

A UNASUL pretende aliar todos os aspectos de integração, econômico e comercial, político e físico, o que se torna um projeto ambicioso. $\mathrm{O}$ autor argentino Ignacio Sabbatella afirma que:

La desigual distribución de los recursos en la región
determina que la mitad de los países miembros sean
importadores (Brasil, Chile, Argentina, Uruguay,
Surinam y Guyana, de mayor a menor) y la otra
mitad sean exportadores (Venezuela, Colombia,
Ecuador, Bolivia, Paraguay y Perú, de mayor a
menor), pero si se toma a los doce países de la
UNASUR como una unidad a partir de las políticas
de integración, el balance energético indica que se
trata de un bloque autosuficiente y que inclusive
cuenta con saldos exportables. ${ }^{20}$

O cenário atual identifica que somente acordos bilaterais prosperaram na região. Sabatella cita o exemplo da Argentina, que importa gás natural boliviano, combustíveis fósseis venezuelanos e tem acordos de energia elétrica com Paraguai, Brasil e Uruguai. ${ }^{21}$ O Brasil possui, principalmente, o acordo bilateral de Itaipu com o Paraguai e o acordo de fornecimento de gás com a Bolívia.

Por outra perspectiva, as iniciativas multilaterais não foram bem-sucedidas em razão de conflitos e diferenças de ordem política, institucional e jurídica, como a rede de gasodutos do sul, para a comercialização de gás peruano e boliviano no Cone Sul e o Grande Gasoduto do Sul, que forneceria gás venezuelano para toda a região, favorecendo bastante a Argentina, que poderia adquirir gás por terra, mais barato e mais seguro que a atual via marítima. $^{22}$

O grande desafio de uma integração energética, além dos embates políticos envolvendo interesses estratégi-

20 SABBATELLA, Ignacio. La integración regional y la seguridad energética. Centro cultural de la Cooperación Floreal Gorini (Seminario). p. 4-5. Disponível em: <https://wwwacademia. $\mathrm{edu} / 9219638 / \mathrm{La}$ _integraci\%C3\%B3n_regional_y_la_seguridad_ energ\%C3\%A9tica>. Acesso em: 05 ago. 2015.

21 SABBATELLA, Ignacio. La integración regional y la seguridad energética. Centro cultural de la Cooperación Floreal Gorini (Seminario). p. 5. Disponível em: <https://www.academia. edu/9219638/La_integraci\%C3\%B3n_regional_y_la_seguridad_ energ $\%$ C3\%A9tica $>$. Acesso em: 05 ago. 2015.

22 SABBATELLA, Ignacio. La integración regional y la seguridad energética. Centro cultural de la Cooperación Floreal Gorini (Seminario). p. 5. Disponível em: <https://www.academia. edu/9219638/La_integraci\%C3\%B3n_regional_y_la_seguridad_ energ\% $\%$ C3\%A9tica>. Acesso em: 05 ago. 2015. 
cos dos membros ${ }^{23}$, é a construção de estruturas físicas necessárias para que haja o efetivo compartilhamento dos recursos energéticos. Recursos esses que podem ser gás natural, petróleo ou energia elétrica, transportados mediante gasodutos, oleodutos e linhas de transmissão, respectivamente.

Essas estruturas, em regra, são compartilhadas para redução de custos, melhor eficiência e otimização na sua utilização. $\mathrm{O}$ acesso a terceiros deve ser respeitado, justamente por ser uma infraestrutura de rede. ${ }^{24}$ No caso de dutos e energia elétrica, empresas detentoras de redes de infraestrutura essenciais para transmitir ou distribuir energia passaram a concentrar parcelas relevantes do mercado e a impedir o livre acesso de terceiros às suas redes, afetando a livre concorrência. A regulação surge como um meio de compensar o desequilíbrio existente entre os agentes econômicos.

Muitas vezes, houve a necessidade de criação de consórcios compostos por inúmeras empresas e/ou parcerias público-privadas para assumir a missão de construir e explorar essas redes, o que seria inviável se fosse realizada de forma individual. Como base para concretizar a infraestrutura de redes, o estabelecimento de regras conjuntas para promoção de incentivos ao investimento denotam ser substanciais.

Além da estrutura física, recursos humanos são, também, considerados um desafio. Conforme o coordenador do programa sobre energia em combustão da UNASUL, Luís Fernando Figueira Silva, 03 (três) grandes objetivos serão perseguidos em 2015-2016, que são a (i) formação de recursos humanos, (ii) desenvolvimento de ciência, tecnologia e inovação e (iii) intercâmbio entre os pesquisadores e o desenvolvimento de forma colaborativa em trabalhos laboratoriais e de desenvolvimento científico e tecnológico. Com isso, espera-se que essas ações levem ao compartilhamento de infraestrutura e de equipes. Alguns países têm infraestrutura que outros não têm e podemos desenvolver tecnologia, ciência e inovação usando essa infraestrutura. ${ }^{25}$

23 Um exemplo é o conflito histórico denominado de Guerra do Pacífico, no período de 1879 a 1883, entre Bolívia, Peru e Chile, pelo controle da saída ao mar, em que esse último derrotou os primeiros, dominando a província de Antofagasta, rica em recursos naturais.

24 Vide NESTER, Alexandre Wagner. Regulação e concorrência: compartilhamento de infraestruturas e rede. São Paulo: Dialética, 2006.

25 UNASUL define ações para programa de energia em combustão. Disponível em: < http://www.brasil.gov.br/ciencia-e-tecnologia/2014/10/unasul-define-acoes-para-programa-de-energia-emcombustao >. Acesso em: 10 jul. 2015.
No setor de energia, a integração e a complementação dos recursos do continente Sul-Americano nas áreas de petróleo e gás e derivados, em termos de integração e troca de combustíveis, como o gás natural e as empresas de transmissão de eletricidade, constituem um eixo aproximação entre os países da região, que deve ser expandido e melhorado juntamente à preservação do meio ambiente e à eliminação de barreiras injustificáveis decorrentes de restrições e regulamentos nesse setor. ${ }^{26}$

E, quando se trata de segurança energética, necessariamente deve ser considerada a diversificação de fontes. Não seria lógico priorizar a construção de oleodutos se a ideia no futuro é compartilhar energia elétrica advinda de fontes renováveis, por exemplo.

Cristine Koehler Zanella defende o gás como um combustível-ponte, entre uma sociedade consumidora de petróleo para uma sociedade consumidora de energia elétrica proveniente de fontes renováveis. ${ }^{27}$ Essa posição se justifica pelo momento em que foi elaborada sua obra, em 2009, cuja tecnologia dos painéis fotovoltaicos e turbinas eólicas, por exemplo, ainda eram escassas e inviáveis economicamente.

O gás importado pelo Brasil e Argentina, por exemplo, é utilizado para geração de energia elétrica por termelétricas, o que leva à afirmação de que é necessário investir em gasodutos. Mas também é necessário investir em linhas de transmissão de energia elétrica, diante da iminente tendência de crescimento de geração de energia também por fontes renováveis, em razão do comprovado potencial. ${ }^{28}$

Ressalta-se que inexiste hoje na América do Sul o estabelecimento de um conjunto de acordos pelos países no intuito de promover maior integração do setor, que requer conexões físicas de intercâmbio de energia e projetos de geração conjuntos. Conforme Moreira e Pinto,

26 ARTIGO 42 do Comunicado de Brasília da Reunião de Presidentes da América do Sul, Brasília, 31 de agosto e 01 septiembre de 2000. Disponível em: <http://www.comunidadandina.org/documentos/dec_int/di1-9-00.htm>. Acesso em: 05 ago. 2015

27 ZANELLA, Cristine Koehler. Energia e integração: oportunidade e potencialidades da integração gasifera na América do Sul. Ijuí: Unijuí, 2009. p. 68.

28 MOREIRA, João Manoel Losada; PINTO, Roberto Tadeu Soares. Integração energética ou integração de mercados: qual é a melhor solução para a comercialização de energia elétrica? In: CONGRESO DE LA ASOCIACIÓN LATIONAMERICANA DE ECONOMÍA DE LA ENERGÍA, 4., 2013, Montevideo. Anais 2013. 
trabalhos acadêmicos foram elaborados como meio de integração, além de iniciativas por outras organizações, mas, em regra, há uma ausência de medidas:

[...] definindo um plano efetivo de ações com marcos regulatórios, papéis e responsabilidades para os principais atores (reguladores, operadores de rede, operadores de mercado, geradores, comercializadores, bolsas de energia, câmaras de compensação, distribuidores, consumidores livres, consumidores cativos e outros). ${ }^{29}$

Eduardo Noboa cita a necessidade de que a integração energética não seja apenas para fins econômicos, comerciais e técnicos, mas que possa ser um meio de prover acesso de energia a todos, favorecendo o desenvolvimento em todos os setores. Ele afirma que a integração energética faz renascer o conceito de integração:

[...] en donde renace el concepto y el momento de la Hora Americana y en donde se requiere de una firme voluntad política; de la disponibilidad de recursos energéticos y de la capacidad de llegar a acuerdos de beneficio mutuo entre los países de la región para alcanzar la verdadera integración. Actualmente, contamos con las dos primeras condiciones (voluntad política y disponibilidad de recursos); sin embargo, debemos continuar trabajando arduamente con plena conciencia de que la integración es una necesidad ineludible y encontrar espacios de consenso en donde nazcan acuerdos de largo plazo y de beneficio mutuo, independientemente de los modelos de desarrollo y de las tendencias políticas individuales de cada país. ${ }^{30}$ (grifa-se).

Estudos apontam sobre as externalidades positivas da integração energética na América do Sul, alcançando benefícios além dos ganhos puramente econômicos, mas outros como:

[...] relações com a efetiva integração; redução das assimetrias regionais e aumento da equidade social; potencial para futura unidade e paz; papel de médio/longo prazo no desenvolvimento regional; permite defesa de "visões próprias" do processo; incorporação de novos agentes nas decisões; segurança energética e aumento da confiabilidade do sistema; solução de gargalos comuns baseada em ganhos mútuos; oferta de serviço mais eficiente,

29 MOREIRA, João Manoel Losada; PINTO, Roberto Tadeu Soares. Integração energética ou integração de mercados: qual é a melhor solução para a comercialização de energia elétrica? In: CONGRESO DE LA ASOCIACIÓN LATIONAMERICANA DE ECONOMÍA DE LA ENERGÍA, 4., 2013, Montevideo. Anais. 2013. p. 4.

30 NOBOA, Eduardo. El sector energético em Suramérica: evolución, potencial e integración, Friedrich Ebert Stitung, nov. 2013. Disponível em: <http://library.fes.de/pdf-files/bueros/quito/10374-20131204.pdf>. Acesso em: 25 jan. 2015. de maior qualidade e com menor custo; exploração de sinergias derivadas da complementaridade hidrológica; expertise e dotação de recursos de determinados países; e existência de fontes de financiamento. ${ }^{31}$

Integrar é dialogar, cooperar e efetivar ações em conjunto, e o desafio é sempre complexo por envolver inúmeras partes, além do fato de que o tema é altamente complexo e estratégico. A América do Sul carece de organização para atingir um fim maior que é o benefício mútuo no compartilhamento de estruturas, justamente para possibilitar maior trânsito ou fluxo de recursos, com custo reduzido, diante da proximidade e da existência de mercado, ou pela solidariedade entre os países vizinhos.

\section{Energia no Tratado Constitutivo da UNASUL}

O Tratado Constitutivo da UNASUL (TCUNASUL) está em vigor desde 2011 e possui inúmeros objetivos. O seu artigo $1^{\circ}$ prevê a organização como pessoa jurídica de direito internacional, com objetivo de promover a integração em diversos temas, entre eles o cultural, social, político, econômico, incluindo o setor energético (vide art. $2^{\circ}$, do TCUNASUL).

Entre outras preocupações, como defesa, educação, saúde, ciência e tecnologia etc., o artigo $3^{\circ}$, do TCUNASUL, dispõe alguns objetivos específicos diretamente relacionados com o tema da integração energética:

La Unión de Naciones Suramericanas tiene como objetivos específicos: (...);

d) La integración energética para el aprovechamiento integral, sostenible y solidario de los recursos de la región;

e) El desarrollo de una infraestructura para la interconexión de la región y entre nuestros pueblos de acuerdo a criterios de desarrollo social y económico sustentables;

$[\ldots]$;

g) La protección de la biodiversidad, los recursos hídricos y los ecosistemas, así como la cooperación en la prevención de las catástrofes y en la lucha

31 SANTOS, Thauan. Integração energética na América do Sul: desdobramentos do desenvolvimento institucional. 2014. 132 f. Dissertação (Mestrado)-Instituto de Relações Internacionais, Pontifícia Universidade Católica do Rio de Janeiro, Rio de Janeiro, 2014. p. 119. 
contra las causas y los efectos del cambio climático; $[\ldots] .{ }^{32}$

O item $d$ realça a aplicação dos princípios do desenvolvimento sustentável e da solidariedade ao frisar o aproveitamento integral dos recursos energéticos entre os membros da organização.

Essa ideia fica mais forte ao combinar com os itens $e$ e $g$, que adota a necessidade de conexão entre regiões mediante a construção de infraestruturas conforme critérios de desenvolvimento sustentável, calcado nos valores sociais, econômicos e ambientais, e pela proteção ao meio ambiente, com a aplicação do princípio da prevenção de forma cooperada para promover a redução de catástrofes ambientais e mitigar as causas e efeitos da mudança climática.

Verifica-se que a organização já nasce com objetivos que podem ser considerados atuais, no sentido de fornecer bases para o incentivo de geração e consumo de energia proveniente de fontes renováveis, por exemplo. Identifica-se uma convergência entre os objetivos específicos da UNASUL com os princípios de desenvolvimento sustentável (Sustainable Development Goals) emitidos recentemente pela Organização das Nações Unidas $(\mathrm{ONU})^{33}$, senão vejamos:

\section{$[\ldots]$;}

Goal 7. Ensure access to affordable, reliable, sustainable and modern energy for all;

Goal 9. Build resilient infrastructure, promote inclusive and sustainable industrialization and foster innovation;

Goal 10. Reduce inequality within and among countries;

Goal 11. Make cities and human settlements inclusive, safe, resilient and sustainable;

Goal 12. Ensure sustainable consumption and production patterns;

Goal 13. Take urgent action to combat climate change and its impacts;

32 UNIÃO DE NAÇÕES SUL-AMERICANAS. Tratado Constitutivo da União das Nações Sul-Americanas. Disponível em: <http:/ / www. unasursg.org/images/descargas/DOCUMENTOS\%20CONSTITUTIVOS $\% 20 D E \% 20 U N A S U R /$ Tratado-UNASUR-solo.pdf>. Acesso em: 10 jul. 2015.

33 ORGANIZAÇÃO DAS NAÇÕES UNIDAS. Transforming our world: the 2030 agenda for sustainable development: finalised text for adoption (1 August). Disponível em: <https://sustainabledevelopment.un.org/content/documents/7891TRANSFORMING\%20 OUR\%20WORLD.pdf>. Acesso em: 04 ago. 2015.
Goal 14. Conserve and sustainably use the oceans, seas and marine resources for sustainable development;

Goal 15. Protect, restore and promote sustainable use of terrestrial ecosystems, sustainably manage forests, combat desertification, and halt and reverse land degradation and halt biodiversity loss; (...). (grifa-se)

Ambas as organizações possuem objetivos de combater as causas e efeitos do câmbio climático, proteção ao meio ambiente, construção de infraestruturas sustentáveis, promover acesso universal e sustentável de energia, no intuito de desenvolver a região de modo sustentável e que não comprometa a qualidade de vida das futuras gerações.

Em 2007, como parte da $1^{a}$ Cúpula Energética Sul-Americana, realizada em Isla Margarita, na Venezuela, mediante a denominada Declaração de Margarita, foi criado o Conselho de Energia Sul-Americano (CES) da UNASUL, quando ainda havia a Comunidade Sul-Americana das Nações.

O CES é composto pelos Ministros de Energia de cada país, e, naquela ocasião, se comprometeram a apresentar proposta de diretrizes para a Estratégia Energética Sul-Americana, para o Plano de Ação e do Tratado de Energia Sul-Americano. Essas tarefas foram delegadas ao Grupo de Especialistas em Energia, sob a chancela do CES.

Somente em maio de 2010, na Reunião Presidencial Extraordinária, o CES aprovou o estabelecimento de (i) Diretrizes do Plano de Ação para a Integração Regional de Energia com base em linhas de ação estratégicas referentes a petróleo, gás natural, carvão, energia elétrica, energia alternativa, energia nuclear e eficiência energética; (ii) Estrutura do Tratado Energético Sul-Americano: considerado como o marco jurídico para concretizar a integração energética regional; e (iii) Diretrizes de Estratégia Energética. ${ }^{34}$

Nessa ocasião, os Ministros da Energia ficaram encarregados de avançar o desenvolvimento do conteúdo do Tratado. Nesse quadro inicial de planejamento, verifica-se a existência de boas intenções das partes em promover a integração regional energética. Mas para

34 SISTEMA ECONÓMICO LATINOAMERICANO Y DEL CARIBE. Temas centrales en la creación del Organismo ha sido los de energía e infraestructura Art. 3 Tratado Constitutivo literal d) y e). Disponível em: <http://www.sela.org/media/265920/t023600004442-0-unasur_ temas_de_energia_e_infraestructura.pdf > . Acesso em: 05 ago. 2015 
que haja efetivamente um comprometimento em realizar essa integração, a aprovação e vigência do Tratado de Energia Sul-Americano (TES) se revela essencial.

\section{Proposta de um Tratado de Energia Sul- Americano (TES)}

O Conselho de Energia Sul-Americano (CES) ficou responsável pela cooperação e complementação em matéria de energia na região. ${ }^{35}$ Seus objetivos são assegurar:

Direito soberano ao uso dos recursos naturais e à gestão das taxas de exploração;

Respeito às regras de cada país e as formas de propriedade adotadas por cada Estado para o desenvolvimento dos seus recursos energéticos;

Solidariedade e reciprocidade;

Eliminar as assimetrias entre os Estados;

Respeito à soberania e autodeterminação dos povos;

Princípio da integridade territorial.

Os objetivos acima refletem normas gerais para concretização de um Tratado. Abaixo seguem algumas diretrizes estabelecidas pelo Conselho, no intuito de promover a integração energética Sul-Americana:

- Promover a segurança energética da região;

- Reforçar a infraestrutura energética regional;

- Promover o intercâmbio e transferência de tecnologia;

- Incentivar o desenvolvimento energético regional;

- Promover a industrialização e desenvolvimento do setor de energia;

- Promover a harmonização dos aspectos regulatórios e comerciais relacionados com a integração energética;

- Incorporar ao planejamento doméstico de cada membro o objetivo de integração regional de energia;

- Promover o uso eficiente da energia;

- Promover o desenvolvimento de energias renováveis e alternativas;

- Incentivar as parcerias entre o setor público e privado;

- Promover o equilíbrio entre países produtores e os consumidores de energia.

35 UNIÃO DE NAÇÕES SUL-AMERICANAS. Consejo Energético Suramericano De Unasur (CES). Disponível em: <https:// www.unasursg.org/es/node/22>. Acesso em: 05 ago. 2015.
As diretrizes acima são bem específicas, e merecem maior detalhamento quando da formulação de um tratado multilateral. É possível constatar que a segurança energética e o desenvolvimento regional são os vetores principais da integração energética, convergindo para o núcleo centralizador referido no início deste trabalho. A partir desses grandes eixos, podem se extrair as demais diretrizes como eficiência energética, investimentos em infraestrutura, harmonização jurídica, transferência de tecnologia etc.

O CES foi encarregado para a elaboração do Tratado Energético Sul-Americano (TES), que reflete as diretrizes e princípios estabelecidos. ${ }^{36} \mathrm{O}$ primeiro draft do TES consiste em um preâmbulo e sete partes, que apresentam dispositivos que parecem contemplar as necessidades do setor, como infraestrutura, marcos regulatórios, segurança energética, investimentos, livre trânsito, segurança jurídica, tarifas, meio ambiente, cooperação, relação com outros tratados e até mesmo prevendo um mecanismo de soluções de controvérsias ${ }^{37}$.

Em maio de 2015, a IV Cúpula do Conselho Energético não produziu resultados significativos, limitando-se ao recorrente discurso de necessidade de incentivar redes regionais de conexão energética, com acordos regionais que beneficiem o continente, além de lançar um plano de trabalho 2015-2016. ${ }^{38}$

Interessante notar que a própria UNASUL parece ter desacelerado o projeto do TES desde 2010, ao publicar o título UNASUR relanza el Consejo Enérgetico quando da IV Cúpula, além de não aprofundar ou publicar informações sobre o texto ou negociações do próprio Tratado no seu site na internet. Mais preocupante é a ausência de citação do Ministro de Energia do Brasil na reunião.

36 UNIÃO DE NAÇÕES SUL-AMERICANAS. Diretrizes de estratégia energética. Disponível em: <http://www.unasursg. org/images/descargas/ESTATUTOS $\% 20$ CONSEJOS $\% 20$ MINISTERIALES $\%$ f20SECTORIALES/LINEAMIENTOS $\% 20$ DE\%20ESTRATEGIA\%20ENERGETICA\%20SURAMERICANA.pd >. Acesso em: 20 jul. 2015.

37 Em relação ao mecanismo de solução de controversas, necessário observar eventual conflito de normas e/ou de jurisdição emergente do caso concreto, como em Tratados que os membros também são partes. Sobre o assunto, ver: MOROSINI, Fabio Costa; NIENCHESKI, Luisa Zuardi. A relação entre os tratados multilaterais ambientais e os acordos da OMC: é possível conciliar o conflito? Revista de Direito Internacional, Brasília, v. 12, n. 2, p. 150-168, 2014.

38 UNIÃO DE NAÇÕES SUL-AMERICANAS. UNASUR relanza el Consejo Energético. Disponível em: <http://www.unasursg. org/es/node/251>. Acesso em: 05 ago. 2015. 
A Ata da XIX Reunião do Grupo de Especialistas de Energia do CES da UNASUL, de agosto de 2015, é o último documento disponível até a presente data e dispõe sobre a necessidade de continuar trabalhando para o fortalecimento da metodologia para elaboração do Balanço Energético Sul-Americano (BES), alinhadas com as metodologias de cada membro. Percebe-se que a OLADE é uma parceira extremamente atuante dentro do CES, pela sua relevância e corpo técnico sobre o assunto. Ainda, refere que o CES trabalha em conjunto com o Consejo Suramericano De Infraestructura $Y$ Planeamiento (COSIPLAN), o qual, por sua vez, possui trabalhos conjuntos com a Iniciativa para la Integración de la Infraestructura Regional Suramericana (IIRSA), no intuito de coordenar projetos de infraestrutura que envolvam o tema da energia. Em relação ao TES, foi ressaltada a necessidade de análise do relatório elaborado pela OLA$\mathrm{DE}^{39}$, no sentido de reduzir ou harmonizar assimetrias entre os membros para viabilizar um avanço nas negociações. Mesmo tendo sido traçado um plano de metas para 2015/2016, verifica-se uma despreocupação sobre o assunto e as frequentes trocas de representantes dos governos dos membros e a complexidade, e sensibilidade do tema parecem ser um óbice para de fato para se estabelecer um marco regulatório no continente. ${ }^{40}$

Conforme Adilson de Oliveira, é necessário superar três obstáculos para atingir uma integração: the coordination of the electricity output of the various power plants in the region; the environmental licensing of energy projects, especially in Amazonia; and, in particular, the deficit in terms of a legal system to facilitate private investment. ${ }^{41}$ De fato, o TES abrange esses temas de forma mais geral, mas deixa de aprofundar

39 ORGANIZACION LATINO AMERICANA DE ENERGIA. Potencialidades de recursos energeticos y minerales en america del sur: coincidencias juridicas hacia una estrategia regional. Disponível em: < http:/ / www.olade.org/sites/default/files/publicaciones/Potencial-Recursos-Energeticos-Minerales-AS.pdf>. Acesso em: 15 ago. 2015.

40 UNIÃO DE NAÇÕES SUL-AMERICANAS. Ata da XIX reunião de especialistas de energia do CES. Disponível em: <https:// repo.unasursg.org/alfresco/service/unasursg/documents/content/ACTA_DE_LA_DECIMA_NOVENA_REUNION_DEL_ GRUPO_DE_EXPERTOS_EN_ENERGIA_DEL_CONSEJO_ENERGETICO_DE_SURAMERICA_DE_LA_UNION_DE_NACIONES_SURAMERICANAS__UNASUR. pdf?noderef $=07 b 5 \mathrm{cf05}-\mathrm{a} 66 \mathrm{~d}-4568-8 \mathrm{a} 77-\mathrm{d} 6 \mathrm{f} 6241 \mathrm{c} 7 \mathrm{~b} 20>$. Acesso em: 07 mar. 2016.

41 OLIVEIRA Adilson de. Security in South America: The Role of Brazil.Manitoba: International Institute for Sustainable Development. 2010. p. 14. Disponível em: <http://www.iisd.org/sites/ default/files/publications/energy_security_south_america.pdf $>$. Acesso em: 23 abr. 2016. a temática, o que sugere o desinteresse das partes em fomentar a celebração de um acordo-base.

A maior dificuldade, no entanto, tende a ser a aplicação da virtude da cooperação entre as partes para solucionar inúmeras questões, como fixação de preço dos ativos energéticos, aspectos ambientais e investimentos. Isso foi identificado no que se refere ao estudo referente à matéria ambiental no próprio Mercosul, em que se constatou uma concorrência regulatória levando ao fenômeno denominado de race to the bottom, cuja competição regulatória pode levar à ausência ou redução da proteção do meio ambiente. Outra constatação foi a ausência de harmonização das regras naquela Organização, a qual é fomentada na União Europeia, por exemplo, no intuito de evitar conflitos. ${ }^{42}$ Dessa forma, o TES deverá considerar a multiplicidade de regulamentos existentes na seara doméstica para poder atingir seu objetivo.

\section{Alternativas enquanto o TES não Se CONCRETIZA}

Diante das identificadas divergências, resta claro que oleodutos e gasodutos provenientes dos principais países produtores (Bolívia e Venezuela) aos importadores (Brasil, Argentina e Chile), são meios de facilitar o fluxo de recursos e fortalecer a economia continental, levando ao maior desenvolvimento da região. Um marco regulatório seria um meio de prover segurança jurídica para viabilizar os fluxos energéticos, na mesma ideia do Energy Charter Treaty, concluído em 1994, cujo principal objetivo foi criar regras para garantir - assegurar - os investimentos no leste europeu. ${ }^{43}$ Inclusive, foi cogitada a hipótese dos países da América do Sul integrarem o Energy Charter, tentativa essa inexitosa. A Venezuela figura como tão somente como observadora convidada. ${ }^{44}$

Mesmo com exemplos concretos problemáticos,

42 VELHO, Rafael Rott de Campos. O Mercosul e a política ambiental: modelos, inconsistências e alternativas, Revista de Direito Internacional, Brasília, v. 9, n. 3, p. 103-128, 2012.

43 GOLDTHAU, Andreas; WITTE, Jan Martin. Global Energy Governance: the new rules of the game. Washington: Brooking Press, 2010. p. 8.

44 OLIVEIRA Adilson de. Security in South America: The Role of Brazil. Manitoba: International Institute for Sustainable Development, 2010. p. 4. Disponível em: <http://www.iisd.org/sites/ default/files/publications/energy_security_south_america.pdf > . Acesso em: 23 abr. 2016. 
como a divergência contratual entre Argentina e Chile, para fornecimento de gás; entre Brasil e Paraguai, em relação ao preço da energia elétrica decorrente do acordo de Itaipu; e entre Bolívia e Brasil, em razão da nacionalização de refinarias da Petrobrás; enquanto não se celebra o desejado tratado multilateral, uma solução pode estar nas negociações ou tratativas no âmbito bilateral ou sub-regional.

No contexto da integração multilateral do mercado de energia elétrica, esse é mais complexo em razão do necessário fortalecimento de mercados sub-regionais, para, posteriormente, avançar sobre um mercado continental. Essa afirmativa está fundamentada na experiência europeia do Nordpool, em que os países escandinavos ${ }^{45}$ criaram um mercado e regulamento próprio para posteriormente fomentar e participar do mercado europeu. ${ }^{46}$

Mas, no âmbito bilateral, verifica-se um interessante exemplo, que foi a conclusão de $411 \mathrm{~km}$ de linha de transmissão no trecho entre Candiota e San Carlos (integração física Brasil- Uruguai), em 2015, que foi financiada com recursos do Uruguai e por meio do Fundo de Convergência Estrutural (Focem), do Mercosul. Esse projeto de interconexão soma-se ao Parque Eólico de Artilleros, inaugurado em fevereiro de 2015. O parque é uma iniciativa pioneira da cooperação entre a empresa uruguaia UTE e a Eletrobrás, primeiro projeto fora do Brasil na área de geração de energia renovável, financiado pela Corporación Andina de Fomento (CAF). ${ }^{47}$

Outro exemplo de integração está na hipótese de geração de energia hidroelétrica considerando a extensão territorial do continente. Em alguns períodos do ano, a água é escassa em alguns locais e, em outros, abundante (períodos de seca e chuva); mas em regra, quando chove no norte, é seco no sul, e vice-versa (vide exemplo recente do Brasil, com seca recorde em São Paulo). Uma vez interligado o sistema elétrico entre os países

45 Originalmente Suécia, Noruega, Dinamarca, Finlândia, posteriormente Alemanha, Letônia, Estônia, Lituânia, Polônia, Bélgica, Holanda e Grã-Bretanha. Disponível em: <http://www.nordpoolspot.com/TAS/>. Acesso em: 10 ago. 2015.

46 MOREIRA; João Manoel Losada; PINTO, Roberto Tadeu Soares. Integração energética ou integração de mercados: qual é a melhor solução para a comercialização de energia elétrica? In: CONGRESO DE LA ASOCIACIÓN LATIONAMERICANA DE ECONOMÍA DE LA ENERGÍA, 4., 2013, Montevideo. Anais. 2013. p. 9-11.

47 INTEGRAÇÃO energética. Disponível em: < http://blog.planalto.gov.br/assunto/unasul/> Acesso em: 05 ago. 2015.
Sul-Americanos, a energia gerada no sul do continente abasteceria o norte e, noutro período, a energia gerada no norte poderia abastecer o sul, o que levaria à redução de custo e a uma eficiência ótima.

Isso vai de encontro com uma das modalidades de exportação e importação de eletricidade, que utiliza condições favoráveis de um país e desfavoráveis de outro, no intuito de assegurar abastecimento a todos os participantes:

Importação/Exportação com caracterização de energia de oportunidade: condições hidrológicas favoráveis em um país $\mathrm{A}$, viabilizam a exportação de excedentes de energia elétrica, de origem hidráulica, para um país B interligado, sem comprometimento de atendimento a demanda do país A e com vantagens para ambos. Considera-se, por exemplo, a variação na sazonalidade do clima entre os países. Nesta modalidade, as perdas são rateadas e a devolução deve ser realizada em montantes de energia, não envolvendo transações financeiras. (grifa-se) $^{48}$

Adilson de Oliveira ressalta interessante perspectiva sobre os benefícios de uma integração energética, defendendo a cooperação da geração e consumo de energia, reduzindo custos, investimentos e impacto ao meio ambiente, além de aumento da segurança energética:

This hydrological diversity offers opportunities to explore hydropower generation in the rainy season in certain river basins to compensate for the inability to generate power in other river basins that experience low rainfall. The cooperative generation of hydropower reduces the need to burn fuel in thermal plants. The cost of electricity is reduced, the environment suffers lower impacts and the risk of power shortages diminishes. The diversity in consumer behaviour leads to demand for power peaking at different times. The cooperative use of regional power generation capacity reduces the need for installed capacity to secure regional energy supplies. Investments are smaller and the cost of electricity is reduced. ${ }^{49}$

Obviamente, deverá ocorrer uma confiança mútua para esse sistema vingar, pois um membro fornecerá energia ao sistema em determinado

48 MOREIRA; João Manoel Losada; PINTO, Roberto Tadeu Soares. Integração energética ou integração de mercados: qual é a melhor solução para a comercialização de energia elétrica? In: CONGRESO DE LA ASOCIACIÓN LATIONAMERICANA DE ECONOMÍA DE LA ENERGÍA, 4., 2013, Montevideo. Anais. 2013. p. 6.

49 OLIVEIRA Adilson de. Security in South America: The Role of Brazil.Manitoba: International Institute for Sustainable Development, 2010. p. 5. Disponível em: <http://www.iisd.org/sites/ default/files/publications/energy_security_south_america.pdf>, Acesso em: 23 abr. 2016. 
período e o outro deverá realizar o mesmo noutro período, conforme o potencial hidrológico, não se cogitando bloqueios no abastecimento. A segurança energética acaba sendo o foco de discussão no caso concreto. Um sistema de solução de controvérsias deverá ser criado para eventual litígio. ${ }^{50}$

O que merece ser salientado é que a América do Sul integrada poderia ser considerada como uma potência global energética - condicionado a alguns ajustes - na perspectiva de alcançar maior autonomia em face da comprovada abundância de recursos, mercado, e com acesso aos oceanos Atlântico e Pacífico. A Venezuela e Bolívia, produtores de petróleo e gás, respectivamente, além de Brasil, Argentina, como maiores consumidores e produtores em menor escala, além da Colômbia como produtora de carvão e petróleo, são indícios que elevam a esse patamar. Estima-se um PIB da ordem de US\$ 3.031 trilhões, em que o Brasil contribuiria com US\$ 1,990 trilhão, considerando a paridade do poder de compra. ${ }^{51}$ Esse dado, inclusive, deveria ser melhor explorado pelo Brasil para atuar como um líder regional, incentivando a celebração de um marco regulatório, já que na teoria seria o maior beneficiado pelo aumento de fluxos energéticos.

O Brasil, figurando como uma liderança regional, estando numa localização central do continente com mercado relevante e detentor de recursos naturais abundantes, mediante uma integração energética regional, poderia liderar os demais países para uma transição gradual para uma economia de baixo carbono. Isso desencadearia outro benefício:

South America's position in the global process of energy transition will be largely determined by its capacity to secure the region's energy supplies and to offer safe energy supplies to energy-importing countries outside South America. Access to consumer markets in these countries will create a favourable economic environment for attracting investments to the region, thus adding value to its vast energy resources, whether renewable or nonrenewable. $^{52}$

No entanto, hoje e infelizmente, o continente Sul-Americano carece de políticas mais efetivas. Com exce-

50 THORSTENSEN, Vera; et. al. A regulação do comércio internacional de energia: combustiveis e energia elétrica. São Paulo: FIESP, 2013. p. 309-310.

51 BANDEIRA, Luiz Alberto Moniz. Geopolítica e politica exterior: Estados Unidos, Brasil e América do Sul. Brasília: FUNAG, 2010. p. 118.

52 OLIVEIRA Adilson de. Security in South America: The Role of Brazil.Manitoba: International Institute for Sustainable Development, 2010. Disponível em: < http://www.iisd.org/library/energysecurity-south-america-role-brazil>. Acesso em: 23 abr. 2016. ção da Aliança do Pacífico, que adota o modelo norte-americano de acordos comerciais regionais, os demais países, como o Brasil, não participam ativamente dessa nova realidade, apostando sempre na multilateralização das relações, permanecendo vinculados a acordos regionais pretéritos..$^{53} \mathrm{O}$ estabelecimento de um tratado energético no continente poderia quebrar esse paradigma negativo.

Alternativamente, algumas organizações específicas na área de energia merecem destaque na região, como a Iniciativa para la Integracion de la Infraestructura Regional Suramericana (IIRSA), que planeja projetos no continente e funciona como apoio técnico da UNASUL ${ }^{54}$; e a Organização Latino Americana de Energia (OLADE), criada em 1973, atuando como apoio técnico em que os membros atuam conjuntamente para a integração energética regional, mediante comercialização e defesa dos recursos energéticos. ${ }^{55}$

Outra organização - esta não governamental - é a Comissão de Integração Energética Regional (CIER), criada em 1964, atuando mais precisamente na integração do setor elétrico, cujos estudos demonstram que existe oportunidade para aprofundar a integração energética da região, com maior eficiência na utilização de recursos, compartilhamento de linhas de transmissão, melhor qualidade na prestação de serviços, tarifas mais eficientes e um ambiente regulatório mais favorável à competitividade. ${ }^{56}$

Todas as iniciativas que fomentam uma maior segurança energética devem ser estimuladas, principalmente quando ambicionam políticas para acesso universal à energia, qualidade de vida e demais benefícios. Projetos bilaterais são positivos, mas possuem a desvantagem que acabam sendo pontuais e atingem somente os contratantes, sem um planejamento coletivo mais robusto, que um tratado no âmbito da UNASUL poderia oferecer.

53 CAPUCIO, Camila. A OMC e o regionalismo do século XXI: estratégia de imposição de modelos normativos? Revista de Direito Internacional, Brasília, v. 12, n. 2, 2014 p. 336-348.

54 IIRSA. Proyectos. Disponível em: <http://www.iirsa.org/Projects $/$ Search?menuItemId=97>. Acesso em: 05 ago. 2015.

55 THORSTENSEN, Vera; et. al. A regulação do comércio internacional de energia: combustiveis e energia elétrica. São Paulo: FIESP, 2013. p. 306.

56 THORSTENSEN, Vera; et. al. A regulação do comércio internacional de energia: combustiveis e energia elétrica. São Paulo: FIESP, 2013. p. 307-310. 


\section{Considerações finais}

É inequívoco que a integração regional promove a segurança energética, cujos benefícios são latentes, desde os aspectos económicos sociais à redução de impacto ao meio ambiente, promovendo um macro desenvolvimento sustentável. ${ }^{57}$ São inequívocos os potenciais benefícios de uma eventual facilitação dos fluxos energéticos, confirmando a hipótese levantada neste trabalho, mas desde que as receitas sejam direcionadas para setores catalisadores do desenvolvimento ${ }^{58}$, como tecnologia, defesa, qualidade de vida (saúde e educação), transporte, segurança, infraestrutura e energia.

O Tratado Energético (TES) é ainda uma promessa e seus projetos e estudos que fundamentaram a ideia de uma integração continental dificilmente sairão do papel nos próximos anos por algumas razões. Primeiro, se verifica que suas diretrizes são relevantes mas tendem a se situar num campo mais genérico. Um exemplo é a ausência de previsões sobre segurança nos investimentos e licenciamentos ambientais. Acordo semelhante (Energy Charter Treaty) foi justamente criado para assegurar investimentos de infraestrutura de energética no leste europeu após 1990, o que ilustra a viabilidade de (i) os países Sul-Americanos aderirem esse acordo - cuja adesão não foi acolhida - ou (ii) celebrarem acordo regional, que poderia ser o TES.

Segundo, a ausência de vontade política dos países, ou melhor, a instabilidade política do país que deveria liderar esse movimento, o Brasil, fomenta a dispersão para maior integração. Terceiro, a atual e grave situação econômica de três grandes economias da região, quais sejam, Argentina, Brasil e Venezuela, eliminam fontes de financiamento para a construção de infraestruturas.

De qualquer sorte, sugere-se que os membros da UNASUL priorizem a celebração do TES como um objetivo primordial a ser alcançado, no intuito de tornar a América Latina um continente com alto grau de

57 SABBATELLA, Ignacio. La integración regional y la seguridad energética. Centro cultural de la Cooperación Floreal Gorini (Seminário). p. 5. Disponível em: <https://wwwacademia. edu/9219638/La_integraci\%C3\%B3n_regional_y_la_seguridad_ energ\%C3\%A9tica>. Acesso em: 05 ago. 2015.

58 Para maior aprofundamento do conceito de desenvolvimento, que considera não apenas crescimento econômico ou da renda, mas todo o contexto social, como igualdade de oportunidades, qualidade de vida, entre outros critérios, vide SEN, Amartya. Desenvolvimento como liberdade. São Paulo: Cia das Letras, 2010. segurança energética (e jurídica), sob pena de mitigar ainda mais o desenvolvimento da região, historicamente defasado. Por outra perspectiva, a criação de um tratado multilateral sobre sistema de reservas de recursos energéticos para emergências (Reserva Multilateral de Segurança Energética - RMSA) ${ }^{59}$, nos moldes da Agência Internacional de Energia - AIE, ${ }^{60}$ pode ser uma medida temporária até uma transição completa de uma economia de alto para baixo carbono.

Alternativamente, enquanto se aguarda a celebração do tratado multilateral, sugere-se que os membros efetivem relevantes projetos bilaterais ou sub-regionais, mesmo que limitados e pontuais. Por fim, apesar da complexidade do tema, acredita-se que investimentos em infraestrutura de linhas de transmissão, em razão do crescimento da geração de energia elétrica em longo prazo, por fontes renováveis ou convencionais, devem ser priorizados.

\section{ReferênCIAS bibLIOGRÁficas}

BANDEIRA, Luiz Alberto Moniz. Geopolitica e politica exterior: Estados Unidos, Brasil e América do Sul. Brasília: FUNAG, 2010.

CAPUCIO, Camila. A OMC e o regionalismo do século XXI: estratégia de imposição de modelos normativos? Revista de Direito Internacional, Brasília, v. 12, n. 2, p. 336348, 2014.

CARMEN, Amalia del. A integração energética na América do Sul: instrumentos jurídicos e institucionais para

59 OLIVEIRA Adilson de. Security in South America: the role of Brazil. Manitoba: International Institute for Sustainable Development, 2010. p. 5. Disponível em: <http://www.iisd.org/sites/ default/files/publications/energy_security_south_america.pdf $>$. Acesso em: 23 abr. 2016.

60 A AIE recomenda que os estoques de petróleo dos países-membros sejam realizados pelas empresas, pelo governo ou por agências, ou uma combinação dos três, para que seja possível se manter por até 90 dias sem precisar de fornecimento externo. Isso evita um prejuízo econômico e social, acalmando os mercados e mantendo o preço estável. Por três vezes esses estoques foram utilizados: houve a liberação das reservas de petróleo na Guerra do Golfo, em 1991; após a passagem dos furacões Katrina e Rita, que danificaram plataformas de petróleo offshore, oleodutos e refinarias de petróleo no Golfo do México, em 2005, e recentemente, em resposta à interrupção prolongada do fornecimento de petróleo pela Líbia, em 2011. Vide em INTERNATIONAL ENERGY AGENCY. How does the IEA respond to major disruptions in the supply of oil? Disponível em: < http://www.iea.org/newsroomandevents/agencyannouncements/how-does-the-iea-respond-to-major--disruptions-in-thesupply-of-oil-2011-03-10-.html> Acesso em: 23 abr. 2016. 
projetos gasíferos regionais. 357 f. Tese (Doutorado)Faculdade de Direito, Universidade do Estado do Rio de Janeiro. 2009. Disponível em: <http://www.dominiopublico.gov.br/download/teste/arqs/cp119143. pdf>. Acesso em: 30 jul. 2015.

COMISSÃO ECONÔMICA PARA A AMÉRICA LATINA E O CARIBE. Physical Infrastructure and Regional Integration. FAL Bulletin, v. 280, n. 12, 2009.

COMUNIDAD ANDINA. Artigo 42 do Comunicado de Brasilia da Reunião de Presidentes da América do Sul. Brasília, 31 de agosto e 01 de setembro de 2000. Disponível em: <http://www.comunidadandina.org/documentos/ dec_int/di1-9-00.htm>. Acesso em: 05 ago. 2015.

CONANT, Melvin A.; GOLD, Fern Racine. A geopolitica energética. Rio de Janeiro: Biblioteca do Exército, 1981.

CORRELJÉ, Aad; VAN DER LINDE, Coby. Energy supply security and geopolitics: a european perspective. Energy Policy, v. 34, n. 5, p. 532-543, 2006.

GOLDTHAU, Andreas; WITTE, Jan Martin. Global Energy Governance: the new rules of the game. Washington: Brooking Press, 2010.

INICIATIVA PARA A INTEGRAÇÃO DA INFRAESTRUTURA REGIONAL SUL-AMERICANA. Proyectos. Disponível em: < http:/ / www.iirsa.org/Projects/ Search?menuItemId=97>. Acesso em: 05 ago. 2015.

INTEGRAÇÃO energética. Disponível em: < http:// blog.planalto.gov.br/assunto/unasul/ > . Acesso em: 05 ago. 2015.

INTERNATIONAL ENERGY AGENCY. How does the IEA respond to major disruptions in the supply of oil? Disponível em: <http://www.iea.org/newsroomandevents/agencyannouncements/how-does-theiea-respond-to-major--disruptions-in-the-supply-ofoil-2011-03-10-.html.> Acesso em: 23 abr. 2016.

LAHOUD, Gustavo. Una aproximación teórica a la soberanía energética e integración regional sudamericana. Centro Latinoamericano de Investigaciones Científicas y Técnicas (CLICe'T). Disponível em: <http://www. cienciayenergia.com/Contenido/pdf/080428_i_gol. pdf>. Acesso em: 30 jul. 2015.

MOREIRA, João Manoel Losada; PINTO, Roberto Tadeu Soares. Integração energética ou integração de mercados: qual é a melhor solução para a comercialização de energia elétrica? In: CONGRESO DE LA ASOCIACIÓN LATIONAMERICANA DE ECONOMÍA DE
LA ENERGÍ, 4., 2013, Montevideo. Anais. 2013.

MOROSINI, Fabio Costa; NIENCHESKI, Luisa Zuardi. A relação entre os tratados multilaterais ambientais e os acordos da OMC: é possível conciliar o conflito? Revista de Direito Internacional, Brasília, v. 12, n. 2, p. 150168, 2014.

NESTER, Alexandre Wagner. Regulação e concorrência: compartilhamento de infraestruturas e rede. São Paulo: Dialética, 2006.

NOBOA, Eduardo. El sector energético em Suramérica: evolución, potencial e integración, Friedrich Ebert Stitung, nov/2013. Disponível em: < http://library.fes.de/pdffiles/bueros/quito/10374-20131204.pdf>. Acesso em: 25 jan. 2015.

OLIVEIRA Adilson de. Security in South America: the role of Brazil. Manitoba: International Institute for Sustainable Development, 2010. Disponível em: <http:/ / www.iisd.org/sites/default/files/publications/energy_security_south_america.pdf e http://www.iisd.org/ library/energy-security-south-america-role-brazil $>$. Acesso em: 23 abr. 2016.

OLIVEIRA, Ana Carolina Vieira de; SALGADO, Rodrigo Souza. Modelos de integração na América do Sul: do Mercosul à Unasul. In: ASSOCIAÇÃO BRASILEIRA DE RELAÇÕES INTERNACIONAIS INSTITUTO DE RELAÇÕES INTERNACIONAIS - USP, ENCONTRO NACIONAL ABRI 2001, 3., 2011, São Paulo. Proceedings. Disponível em: <http://www.proceedings.scielo.br/scielo.php?script $=$ sci_arttext\&pid $=$ MSC0000000122011000100011\&lng =en\&nrm=abn>. Acesso em: 07 ago. 2015.

ORGANIZAÇÃO DAS NAÇÕES UNIDAS. Transforming our world: the 2030 agenda for sustainable development: finalized text for adoption (1 August). Disponível em: <https://sustainabledevelopment.un.org/ content/documents/7891TRANSFORMING $\% 20$ OUR\%20WORLD.pdf>. Acesso em: 04 ago. 2015.

ORGANIZACION LATINOAMERICANA DE ENERGIA. Potencialidades de recursos energéticos y minerales en América del Sur. coincidencias juridicas hacia una estrategia regional. Disponível em: <http://www.olade.org/sites/ default/files/publicaciones/Potencial-Recursos-Energeticos-Minerales-AS.pdf>. Acesso em: 07 mar. 2016.

ORGANIZACION LATINOAMERICANA DE ENERGIA; UNION DE NAÇÕES SURAMERICA- 
NAS. UNASUR: un espacio que consolida la integración energética. Disponível em: <http://www.olade. org/sites/default/files/publicaciones/UNASUR $\% 20$ -\%20Un\%20espacio \%20que \%20-completo.pdf>. Acesso em: 15 jan. 2015.

PAMPLONA, João Batista; CACCIAMALI, Maria Cristina. Recursos naturais e estratégias de desenvolvimento para a América Latina. Revista Pontes, v. 11, n. 3, p. 4-6, maio 2015.

RUIZ-CARO, Ariela. Puntos de conflicto de la cooperación e la integración energética em América Latina y el Caribe. ONU/ CEPAL, 2010. Disponível em: <http://archivo.cepal. org/pdfs/2010/S1000042.pdf>. Acesso em: 30 jul. 2015.

SABBATELLA, Ignacio. La integración regional y la seguridad energética. Centro cultural de la Cooperación Floreal Gorini (Seminario). Disponível em: <https:// www.academia.edu/9219638/La_integraci\%C3\%B3n_ regional_y_la_seguridad_energ\% $\%$ C3\%A9tica $>$. Acesso em: 05 ago. 2015.

SANTOS, Thauan. Integração Energética na América do Sul: desdobramentos do desenvolvimento institucional. 2014. 132 f. Dissertação (Mestrado)-Instituto de Relações Internacionais, Pontifícia Universidade Católica do Rio de Janeiro, Rio de Janeiro, 2014.

SEN, Amartya. Desenvolvimento como liberdade. São Paulo: Cia das Letras, 2010.

SISTEMA ECONÓMICO LATINOAMERICANO Y DEL CARIBE. Temas centrales en la creación del Organismo ha sido los de energía e infraestructura Art. 3 Tratado Constitutivo literal d) y e). Disponível em: <http://www. sela.org/media/265920/t023600004442-0-unasur_temas_de_energia_e_infraestructura.pdf > . Acesso em: 05 ago. 2015

THORSTENSEN, Vera et al. A regulação do comércio internacional de energia: combustiveis e energia elétrica. São Paulo: FIESP, 2013.

UNASUL define ações para programa de energia em combustão. Disponível em: <http://www.brasil.gov. br/ciencia-e-tecnologia/2014/10/unasul-define-acoespara-programa-de-energia-em-combustao $>$. Acesso em: 10 jul. 2015.

UNIÃO DE NAÇÕES SUL-AMERICANAS. Alinhamentos de estratégia energética sul-americanas. Disponível em: $<$ http://www.unasursg.org/images/descargas/ESTA-
TUTOS $\% 20$ CONSEJOS $\% 20$ MINISTERIALES $\% 20$ SECTORIALES/LINEAMIENTOS\%20DE\%20 ESTRATEGIA\%20ENERGETICA\%20SURAMERICANA.pdf>. Acesso em: 15 jan. 2015.

UNIÃO DE NAÇÕES SUL-AMERICANAS. Ata da XIX reunião de especialistas de energia do CES. Disponível em: <https://repo.unasursg.org/alfresco/service/unasursg/documents / content/ACTA_DE_LA_DECIMA_NOVENA_ REUNION_DEL_GRUPO_DE_EXPERTOS_ EN_ENERGIA_DEL_CONSEJO_ENERGETICO_DE_SURAMERICA_DE_LA_UNION_DE_ NACIONES_SURAMERICANAS_UNASUR. pdf?noderef $=07 b 5 c f 05-a 66 d-4568-8 a 77-d 6 f 6241 c 7 b 20>$. Acesso em: 07 mar. 2016.

UNIÃO DE NAÇÕES SUL-AMERICANAS. Consejo Energético Suramericano de Unasur (CES). Disponível em: $<$ https://www.unasursg.org/es/node/22>. Acesso em: 05 ago.2015.

UNIÃO DE NAÇÕES SUL-AMERICANAS. Diretrizes de estratégia energética. Disponível em: <http://www. unasursg.org/images/descargas/ESTATUTOS $\% 20$ CONSEJOS\%20MINISTERIALES\%20SECTORIALES/LINEAMIENTOS\%20DE\%20ESTRATEGIA\%20ENERGETICA\%20SURAMERICANA. pdf>. Acesso em: 20 jul. 2015.

UNIÃO DE NAÇÕES SUL-AMERICANAS. Plano TES. Disponível em: <http://www.unasursg.org/ uploads/e1/77/e17787075555d52b60a86193c81d4 82b/PLAN-TRATADO-ENERGETICO-SURAMERICANO.pdf e em http://www.unasursg.org/ uploads/4c/e6/4ce6db8f6ed4f4e72d157f868f640465/ Declaracio\%CC\%81n-de-las-Autoridades-Nacionalesen-Materia-Energe \%CC\%81 tica-Caracas-Venezuela13-mayo-2011..pdf>. Acesso em 15 jan. 2015.

UNIÃO DE NAÇÕES SUL-AMERICANAS. Tratado Constitutivo da União das Nações Sul-Americanas. Disponível em: <http://www.unasursg.org/images/ descargas/DOCUMENTOS\%20CONSTITUTIVOS\%20DE\%20UNASUR/Tratado-UNASUR-solo. pdf>. Acesso em: 10 jul. 2015.

UNIÃO DE NAÇÕES SUL-AMERICANAS. UNASUR relanza el Consejo Energético. Disponível em: < http:/ / www.unasursg.org/es/node/251>. Acesso em: 05 ago. 2015. 
VELHO, Rafael Rott de Campos. O Mercosul e a política ambiental: modelos, inconsistências e alternativas. Revista de Direito Internacional, Brasília, v. 9, n. 3, p. 103128, 2012.
ZANELLA, Cristine Koehler. Energia e integração: oportunidade e potencialidades da integração gasífera na América do Sul. Ijuí: Unijuí, 2009. 
Para publicar na Revista de Direito Internacional, acesse o endereço eletrônico www.rdi.uniceub.br ou www.brazilianjournal.org.

Observe as normas de publicação, para facilitar e agilizar o trabalho de edição. 